\title{
GSP Plus Status and Income Distribution: A CGE Model for
}

\section{Pakistan}

\author{
Muhammad Shahzad Iqbal * $\quad$ Sofia Anwar ${ }^{\dagger} \quad$ Kakali Mukhopadhay $\ddagger$ \\ Muhammad Aamir Khan $\S$
}

\begin{abstract}
The purpose of the study is to investigate the impact of the Generalised System of Preferences (GSP) plus on a household income of Pakistan. The European Union, the largest trading partner of Pakistan, granted the status of GSP plus to Pakistan in December 2013. The study has used MyGTAP, developed by Minor and Walmsley (2013) to calculate the impact at household level. This MyGTAP model uses the data of the latest available Social Accounting Matrix (SAM) to make changes in the standard GTAP by including multiple types of household and labor. The main findings of the simulations, run under MyGTAP model show a positive change in real GDP, merchandise imports and terms of trade while the first simulation shows a negative change in merchandise exports. Similarly, EBA status of Pakistan in the EU28 shows an increase in the household income with maximum gain by the household of rural Sindh with no agricultural land and a positive change in real wages of most of the factors. However, the large and medium agricultural household types show a negative change in household income in case of first simulation. Comparatively low improvement over urban and non-farm household of rural areas.
\end{abstract}

Keywords: Economic growth, trade, GSP Plus, European Union, CGE model, real GDP, terms of trade, real investment, household income.

\section{Introduction}

For many years EU is the largest importer of Pakistani products. Total exports from Pakistan to the EU during the year 2014 were US $\$ 8.13$ billion which accounted 29 percent of the total exports. It was 21.5 percent in 2012 and 24 percent in 2011. Although the EU is considered to be the dominant importer in Pakistan, but the country always showed a sluggish export growth, especially in terms of commodity diversification. On the other hand, penetration into the EU market remained overdue comparing to other competitors.

Pakistan is a member of the preferential trading system of the EU, ever since its evolution. The examination evident that external trade relations of the EU with the developing countries has been conducted with a number of different channels, principally with the African, Caribbean and Pacific (ACP) states through the Lome Convention, Mediter-

\footnotetext{
*PhD Scholar, Department of Economics, GC University Faisalabad.

E-mail:shahzad.iqbaal@gmail.com

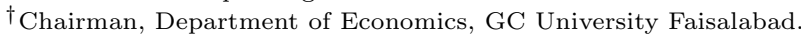

$\ddagger$ Senior Researcher, Department of Natural Resource Sciences, McGill University.

$\S$ Assistant Professor, COMSATS Institute of Information Technology Islamabad.
} 
ranean countries through the Global Mediterranean Policy (GMP) and with the rest of Latin America and Asian developing countries including Pakistan through the GSP scheme. This is evident from the EU's complex network of discriminatory tariff through generalized and country-specific or region-specific trade preferences. While, trade relations with most industrialized countries have been based on most-favoured-nation treatment (Rashid, 2006).

The common commercial policy uses a spread of instruments to regulate trade among the EU and its trade partners. It covers not only tariff, but other trade instruments as well. A complicated system of trade advantages, differentiated according to specific groups of countries, has drawn up to a hierarchy of trade preferences called as 'pyramid' of trade preferences. The examination of EU's trade regime practice worked out over the years points out that it uses fairly complicated procedures and a very elaborate panoply of instruments. Although the system has some of the economic effects hoped for and has been established for political reasons; it seems advisable to simplify considerably in order to expand its benefits largely according to 'trade not aid' principle (Persson \& Wilhelmsson, 2016).

On December 2013, European Union granted GSP plus status and since January 2014, Pakistan has been enjoying this status. It is expected from the very beginning that the exports from Pakistan are expected to increase in the EU market under GSP plus status. This status will substantially increase Pakistan's exports to the EU-28 especially in textile, wearing apparel and leather sectors.

Everything But Arms (EBA) is a status that allows almost everything to be exported to the EU by the beneficiary country. It is considered as a most generous scheme for developing countries like Pakistan, but Pakistan has not been granted this status yet. It is expected that the EBA status may bring more benefits for Pakistan than any other status.

The European Union is the largest export destination for Pakistan. Recently, the EU granted GSP plus status to Pakistan. Our main research problem is to investigate the likely impact of GSP Plus on Pakistan's exports to the European Union and hence its resulting positive effects on economic development. The impact can be underestimated or overestimated if one tries to capture the impact of the FTA like GSP plus by applying partial equilibrium analysis. As all the sectors of the economy are interlinked, so any shock in one sector leads to changes in other sectors. So, the main objective of the study is to find out the impact of GSP plus status of Pakistan in the EU - on Economic growth of the country. To capture the impact of these measures, Computable General Equilibrium models are an ideal tool.

The main objective of the study is to calculate the potential impact of GSP plus on the household income and real wages by applying MyGTAP. The study also aimed to calculate the potential economic gains from GSP plus and EBA in terms of GDP and merchandise exports. The study wants to investigate the possible outcomes from a series of different policy experiments and suggest some policy recommendations. 


\section{Is GSP Plus Different from Normal GSP?}

The basic and foremost objective of the preferential system known as the Generalized System of Preferences (GSP) is to help the economies to reduce the poverty, promote good governance and sustainable economic growth. These preferences enable the economies to increase their role in the international trade and especially the exports to the EU that ultimately help them to reduce the poverty and maintain a sustainable development. The GSP of EU covers the following regimes (European, 2013).

- The standard/normal GSP that covers more than 6300 tariff lines, transports preferences in 90 developing countries that have been reduced from 177 in 2013.

- GSP Plus that brings special arrangements to promote good governance and sustained development in addition to offering duty free access to more goods from the vulnerable economies including Pakistan. The list includes 25 countries, adding 9 more to the previous 16 . The beneficiary economies have to implement and ratify certain international conventions.

- The most attractive arrangements for the 50 Least Developed Economies (LDCs) called Everything But Arms (EBA), provides duty free and quota free access to nearly all commodities.

In addition to the preferential agreements, EU has established trade relations on the basis of Most Favored Nation (MFN) treatment, allowing all industrialized countries outside the EU to trade with.

Identification of 'high potential' products of Pakistan in EU after the GSP plus status is first step that should be followed by the identification of potential competitors with same status or even better. The EU has a range of agreements with different countries, including GSP, GSP plus, Every Thing, but Arms (EBA), Overseas Countries and Territories (OCT), Economic Partnerships Agreement (EPA) and some more. While considering the competition among developing economies, EBA is considered to be more attractive than the GSP plus status (Carbone \& Orbie, 2016).

Although, achieving the status of zero tariff on export of all products is a huge opportunity, but the exports from Pakistan may not observe abrupt jump. It is because Pakistan will continue to face a tough competition from countries enjoying the same or better treatment in the EU market. The countries with GSP plus status will face an annual capping mechanism while others with EBA status like Bangladesh will enjoy the tariff free access throughout the year. In addition to such status in the EU market, the commodity price, production capabilities and demand for the products will also play key role in such a competitive environment. Table 1 below summarizes the position of Pakistan and its competitors with similar status in the EU market.

\section{Literature Review}

Many authors have observed the literature on CGE models applied to less developed and developing countries. 
Naqvi (1998) developed a CGE model and used the SAM 1983-84 aiming to analyse the economy wide impact of energy policy. The results found by the simulation show that a change in energy tax has varied influences on different commodities, i.e. If distortions are removed from taxes on petroleum products, it fulfills the objective of social equity while

Table $\mathbf{1}$
\begin{tabular}{lllllllll}
\multicolumn{1}{l}{ Comparison of Imports by the EU (28) with GSP Plus Beneficiaries (US \$ Million) } \\
\hline S.No & Exporters & $\mathbf{2 0 0 8}$ & $\mathbf{2 0 0 9}$ & $\mathbf{2 0 1 0}$ & $\mathbf{2 0 1 1}$ & $\mathbf{2 0 1 2}$ & $\mathbf{2 0 1 3}$ & $\mathbf{2 0 1 4}$ \\
\hline 1 & Peru & 5757.8 & 4606.1 & 6964.3 & 9044.2 & 8245.5 & 7319.7 & 6829.2 \\
2 & Pakistan & 6068.4 & 5295.4 & 5918.3 & 7485.8 & 6093.2 & 6868.2 & 7220.7 \\
3 & Paraguay & 732.3 & 509.9 & 1313.1 & 1657.4 & 1225.1 & 1574.6 & 1527.6 \\
4 & Costa Rica & 5446.4 & 4516.8 & 5310.1 & 6077.3 & 6790.6 & 6394.6 & 6119.1 \\
5 & Ecuador & 3569.8 & 3078.3 & 3047.4 & 3712.9 & 3601 & 3897.1 & 4003.4 \\
6 & Georgia & 908 & 604.6 & 886.9 & 923.8 & 762.9 & 916.3 & 907.5 \\
7 & Armenia & 478.1 & 241.4 & 323.2 & 443.1 & 330.8 & 329.4 & 335.9 \\
8 & Bolivia & 474.4 & 420.6 & 569.5 & 592.2 & 603.7 & 761.4 & 879.9 \\
9 & Mongolia & 95.4 & 75.7 & 135.9 & 114.9 & 93.3 & 105.6 & 115.8 \\
10 & Cabo Verde & 40.4 & 39.1 & 50.6 & 63.9 & 68.5 & 64.4 & 78.5 \\
\hline Source: & International Trade Centre (ICT) & & & &
\end{tabular}

removal of distortion in taxes on electricity has no impact on the consumption of rural household while it showed a negative impact on urban household. On the other hand, applying a tax on natural gas brought a negative impact on the real consumption of the household. It was further discovered that removing distortions not only increase the real GDP, but also bring a positive change in the trade balance. The model was simply a static model aiming comparative analysis and had nothing to do with the forecasting.

Ghosh (2004) developed a CGE model for Pakistan by using GTAP 4 to investigate the impact of roads and transport infrastructure on the economy. The study proposed a multiregional CGE model in order to check the impact of a new road network between Karachi and Peshawar. The simulation results discovered that new road will bring positive change in the industrial sector of Punjab and NWFP (North West Frontier Province, Now KPK (Khyber Pakhtunkhwa) provinces of Pakistan. The road network will increase the real income of households that ultimately will increase the utility level in both provinces. The study further concluded that this network will bring positive change of $16 \%$ to the GDP of the economy.

Butt (2006) utilized the CGE model for Pakistan to calculate the impact of tariff cuts on the regional disparities, output, employment and exports by keeping in view different regions of the country. The study developed a PAKREG database by utilizing the I-O table of 1990-91 developed by the Federal Bureau of Statistics (FBS 2001). The study in this way helped the GTAP to recognize Pakistan as a separate country. The results of the study revealed a positive impact of trade liberalization on all regions of Pakistan in terms of improvement in output, exports and employment. The results further discovered a positive relationship between trade liberalization and regional disparities during the military regimes and opposite in the case of democratic governments. The cross border tariff cuts seemed to help the increment in real GDP slightly in the short run but significant in the long run.

Ahmed and O'Donoghue (2008) described the welfare effect of the external balances on Pakistan economy. The study used a CGE model to capture economy wide impact of policy 
simulation. Social accounting was used as a database and GAMS software was used to run the model. The study encompassed 12 agriculture sector 16 industrial sector and 6 services sector. Households have been distributed in rural and urban. The rural households have been further distributed into 17 categories. The experiment was performed through trade liberalization simulations. The simulations were concerned with a 50 percent increase in foreign savings, a 10 percent increase in overall import prices and 10 percent increase in the import prices of petroleum etc. The results of the study suggested that the external oil prices possessed the high potential to affect Pakistan socio economic conditions. Increase in foreign saving decrease poverty in the country. The analysis suggested that poverty is increasing with the increase in import prices.

Shaikh and Rahpoto (2009) has studied the SAFTA implication on Pakistan economy using the GTAP model. This study used 10 regions and 10 commodities. The experiments were based on the unilateral trade liberalization (uniform tariff rate 15 percent), regional trade liberalization, and unilateral trade liberalization (15 percent) for the rest of the world. The study used GTAP model to investigate the benefits and costs of granting MFN (Most Favored Nation) status to India and SAFTA. The results highlighted the potential industries which need to be expanded or contracted. Pakistan gained highest welfare in case of SAFTA with 15percent uniform external tariff. There is high demand in the international trade for Pakistani dates, leather and garments etc. The study identified a variety of industries in which a high potential existed. The SAFTA role is important by giving opportunity for member countries to achieve economies of scale, diversify their exports net and improve competitiveness. The study further explored that if SAFTA is fully integrated and Pakistan gets a tariff cut of $15 \%$, it would bring highest welfare gain for the people.

Hussain (2010) applied CGE model using SAM 2002 to investigate the fiscal strictness and the trade liberalization impact on household welfare and inequality. The study explored that there are two principal effects of export taxes and tariffs. Firstly, they reduce the trade volumes on both the import and export sides. Secondly, they impose economic costs by inducing resource mis-allocation. Therefore, if trade related taxes are eliminated, an economy can avoid production and consumption distortions. It is an established fact that free trade leads to enhanced efficiency The case of efficiency for free trade is the converse process to the tariff's cost benefit analysis. The study further discovered that for a small country like Pakistan, imposing a tariff does not allow it to influence world prices. However, prices for domestic consumers and domestic producers do arise as a result. Consequently, imports and consumption are reduced and the production of import substitute increased.

Dorosh and Rashid (2013) utilized CGE models to measure the latest terms of trade for the agriculture sector, comparing it to the industrial sector in Pakistan during the years of 2000-2010 and to study the impact of agriculture income tax on Pakistan economy by using a social accounting matrix (SAM 2002). The result of the experiment showed a $5 \%$ and $10 \%$ increase in the government revenue through the imposition of agriculture tax. The study further elaborated that manufacturing and imports flourished while construction and exports faced decline. The labor demand in the non - agriculture sector raised, whereas the demand for labor in agriculture sector reduced due to increase in the agriculture income tax. 
Siddig, Aguiar, Grethe, Minor, and Walmsley (2014) studied the Nigerian socioeconomic policy impacts of reducing fuel subsidies while employing countrywide framework using the newly developed MyGTAP model. This model incorporated country-specificinformation covering 12 groups of households to examine domestic policies. The study encompassed 13 regions and 21 commodities. My GTAP incorporated government budget in two folds; income and expenditure. It is considered that lowering the fuel prices accompanied by a low level of living cost can be the outcome of subsidies incorporated in the imported goods of the petroleum sector. The study supported a reduction in fuel subsidy policy because it has non-decreasing effects on the household income-especially the poor one-hence leading to alleviate poverty in Nigeria.

Kuiper and Shutes (2014) studied the impact of food and nutrition security on multiple households in Ghana by employing MyGTAP database of Minor and Walmsley (2013). The study involved a multiple household to study the effects of food policy on the most vulnerable sector of the society, helping the government to design intervention in order to provide relief to the poor segment of the society. The study embedded 19 commodities and 9 households. In the study, the following three approaches were used to incorporate multiple household data in GTAP data base. Firstly, user weights has been assigned to household and incorporated in GTAP. Secondly, the study included household data through national SAM. Thirdly, they directly place household survey in GTAP analysis. The result suggested that the removal of export subsidy is useful to the poor people of Ghana.

Khan, Saboor, Mohsin, et al. (2015) developed a CGE model to investigate the impact of agriculture trade liberalization (the elimination of import tariff and the removal of export subsidies) on income inequality of Pakistan. The study adopted the newly developed MyGTAP model developed by Minor and Walmsley (2013). The model used a two kind of data base i.e. GTAP and SAM (2007-08). This study deeply analyzed the impact of agriculture, trade liberalization on multiple households. The study encompassed 18 households, 12 regions and 37 sectors. The results of agricultural trade liberalization suggested that income inequality in Pakistan is increased by $0.49 \%$ from the baseline. Medium and large household types are aided, and there is a nominal increase in the real wages of medium and large agricultural labors. The labor intensive crops are replaced by capital intensive and cheap imported products that ultimately helped to enhance the income inequality in Pakistan.

\section{Rationale for a New CGE Study on Pakistan}

The majority of the CGE studies conducted in Pakistan includes the following issues, changes in tax, food policies, government expenditures and investments, policies related energy crisis, performance of public sector organizations, trade liberalization, Dutch disease effect, unequal distribution of wealth, and poverty conditions in Pakistan.

All of the previous studies conducted in Pakistan using CGE have some common characteristics that include some behavior related phenomenon like producer behavior, consumer behavior and international trade are some common features used by many researchers. Secondly, most of these researchers used Neo classical comparative static CGE model in their studies. These are single country models except (Butt, 2006) who developed PAKREG a 
regional CGE model in the study to discuss the tariff cuts, exports and regional disparities, which aimed to help Global Trade Analysis Project (GTAP) for the trade issues relating to Pakistan.

\section{Methodology}

\section{MyGTAP Model}

The CGE model in its global version is supported by the Global Trade Analysis Project (GTAP) model as it provides the modeling framework as well as the database to the CGE model. That is; the main source of data for the global CGE model is the GTAP database. The model of GTAP is the most commonly used and known software for the multi country trade analysis. It is a multi-region, multi-country and multi- sector CGE model which assumes perfectly competitive markets and return to scale (Burfisher, 2011). GTAP 09 with reference years 2004, 2007 and 2011 to 140 regions, 57 sectors and 244 countries has been used to link the Pakistan economy with the rest of the world in general and the European Union (EU28) in particular.

The study has linked the latest available comprehensive Social Accounting Matrix (SAM) 2007-08 developed by International Food Policy Research Institute (IFPRI) to a latest extension of the standard GTAP to make it MyGTAP. The MyGTAP developed by Minor and Walmsley (2013) is briefly explained here. MyGTAP is developed on the basis of the standard GTAP model which is commonly used for trade analysis focusing the tariffs (Hertel \& Hertel, 1997). A regional household is represented in the standard GTAP which combines the income coming from factors of production (land, labor and capital) and taxes and then distributes it among the private household, savings and government expenditures on the basis of their shares. The standard GTAP provides the details of the structure of the expenditures in the economy. It combines the income from all sources and then determine the expenditures, but it does not require the information that which agent receives the income, taxes or transfers.

The study under consideration not only requires the income to be split into private household and government, but also split the household into further categories (poor and non-poor household). The newly developed MyGTAP explains that government collects revenue from taxes and foreign aid to spend on government expenditures, funding foreign governments, providing subsidies and transferring to households. Budget deficit or surplus is decided on the basis of difference between government spending and income. Income sources for private households on the other hand, are a function of returns to factor endowments (land, labor and capital), net rent on foreign capital and foreign remittances, transfer payments made by the government and other households. The household net income is either spent or save. The impact of gain in trade i.e GSP plus status of Pakistan in the EU28 will be noted upon the change in income of different households, but not on the basis of change in consumption of the household. 


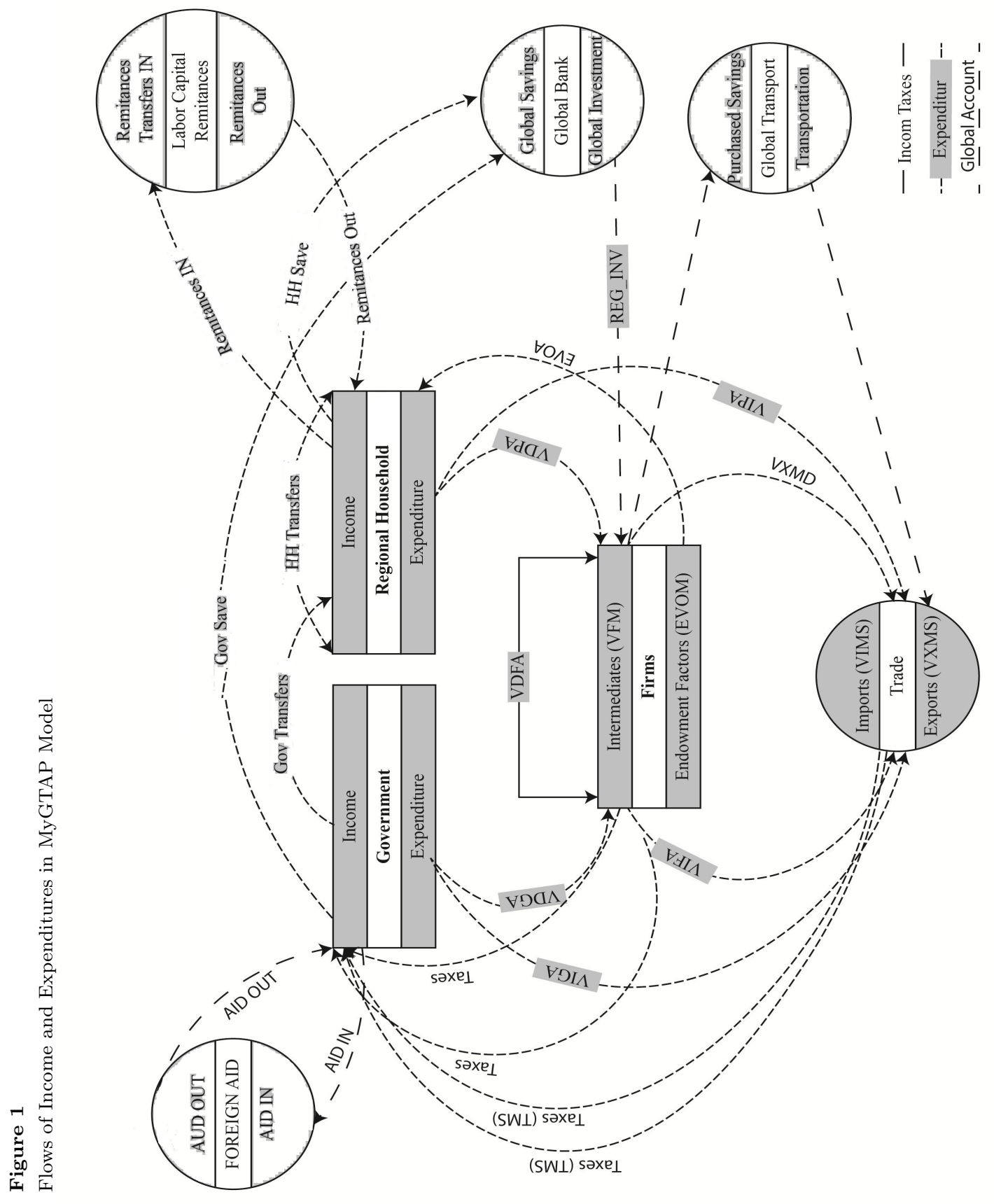




\section{Relationships in MyGTAP Model}

The study has already explained the source of data base in MyGTAP. As discussed earlier, the standard GTAP is modified to make it MyGTAP where the single regional household is replaced with the multiple private households along with a separate government sector for one region (Walmsley, Minor, et al., 2013). Just like in case of standard GTAP, the private households receive income from factors, but in MyGTAP, it also incorporates foreign remittances and capital, which is further used for consumption and saving purpose. The new model assumes that the government sector gains income from taxes and foreign aid in. Government income is consumed on the transfers to the private household and foreign aid out. Moreover, government entertains the receiving of foreign aid instead of the direct acceptance by the private households (Minor \& Walmsley, 2013).

\section{MyGTAP Model Closure}

Model closures are the starting point of this model that assumes perfect competition in all sectors of the economy. Capital and labor as factors of production are considered to be fully mobile among different sectors of the economy and land along with natural resources is immobile. The economy of Pakistan faces the problem of high unemployment rate, so we assumed that unskilled labor (LASKU) are unemployed. Similarly, it is assumed that the factors prices influence the foreign income flows in the respective country. Trade balance is endogenous and expected rate of return determines the investment as in case of standard GTAP model and total domestic savings by the government budget deficit and sum of the private household savings.

Any country that gets GSP Plus status in the EU face the annual growth capping mechanism for products with higher growth rates. The study incorporated the capping mechanism with quota restrictions.

\section{Data Base and Analysis}

\section{Social Accounting Matrix (SAM) for MyGTAP}

Pakistan Institute of Development Economics (PIDE) developed the first Social Accounting Matrix (SAM) for Pakistan in 1985 with base year 1979. Federal bureau of Statistics (FBS) under Project Improvement of National Accounting System (INAS) with collaboration with the Netherland government developed the second SAM that was limited to only single household. Siddiqui and Iqbal (1999) constructed a new SAM for Pakistan with base year 1989-90 and aggregated the industrial classification of Input-Output (IO) table into SAM with five production accounts. Dorosh, Niazi, and Nazli (2004) built a broad SAM with 34 production accounts and 19 household groups with base year 2001-02. These household groups were disaggregated across provincial basis, hence most suited for policy analysis that target particular households. Khan et al. (2015) produced a financial SAM for the year 1999-2000. They disaggregated the workings of the loanable funds market into disaggregated payments related to physical and financial flows among institutions. 
The latest available SAM that depends heavily on concomitant National Accounts and house-hold data was developed by Debowicz, Dorosh, Haider, and Robinson (2007) with base year 2007-08, under the Pakistan Strategy Support Program (PSSP) funded by USAID aiming to support the Government of Pakistan with evidence-based policy reform for pro-poor economic growth and enhanced food security.

To implement a CGE model with an income distribution component, a consistent data base is required. MyGTAP in the study pursues the SAM (2007-08) desegregation of activities, commodities, factors and institutions. The model follows the framework developed by Lofgren et al. (2001). This model is a standard static model rather than dynamic CGE model. Therefore the second period effects of changes in investment expenditures are not taken into account. Moreover, the model neither specific about the time horizon of the adjustment nor how the adjustment is sequenced. Otherwise stated, the model cannot resolve whether adjustment from the base to a new equilibrium takes place over any particular length of time, or whether a large part of the adjustment occurs in a particular year.

SAM provides actual values for the coefficients in these equations through the calibration process. The model will be solved primarily for equilibrium to make sure that the base year dataset is reproduced. Afterward, it would be possible to shock the model with a change in the value of one of the exogenous variables. The model will be resolved for equilibrium and the changes in the values of the endogenous variables. Moreover these values will be compared to those of the base-year equilibrium to establish the impact of the exogenous shock.

To simplify the things, the study aggregated the regions and sectors. The details are presented in appendix.

\section{Simulations}

The study used MyGTAP in order to calculate the impact of two simulations on the real wage rate and household primarily. The base year used in MyGTAP is 2007, as the latest available SAM for Pakistan is of year 2007-08. In addition to calculating the impact of simulations on household income and real wage rate, the study have also discussed some other areas of the economy, taking into account the overall and regional characteristics of the production sectors and factors allocation.

Although the evidence is available that trade liberalization is good for the growth, but how it impact on household income and real wage rate is less clear. Pakistan is a developing country and is more concerned about the effects of EU's GSP plus and EBA status on household income in Pakistan. There are many studies that identified the positive and negative impact of trade liberalization (Hertel \& Hertel, 1997; Winters, McCulloch, \& McKay, 2004; Vanzetti, Huong, et al., 2006). Calculating the impact of GSP plus and EBA status on poor household and different types of labor is important to formulate the policy and planning for sustainable growth.

The study have only used the two following simulations for this purpose.

Simulation I: EU-28 GSP Plus status with quota restriction: What would happen if quota restriction is applied on Pakistan to incorporate the capping mechanism of the EU-28? 
Simulation II: Potential EU28-EBA with Competitors: What would happen if Pakistan gets the Everything But Arms (EBA) status in the EU-28 with no Capping mechanism/Quota restriction, with main competitor Bangladesh that already enjoying the EBA status?

The results of these simulations are presented below.

\section{Results of the Simulations}

\section{GDP and Production}

The results of the both simulations are presented in Table 2 which show positive change in real GDP of Pakistan. In case of first simulation, the GDP of Pakistan increases by US\$ 21.594 million which is 0.015 percent positive change from the base line value. The results of second simulation also very encouraging with positive change of US $\$ 884.047$ million in GDP.

\section{Table 2}

GDP Quantity Index EU, Constant 2007 Prices (Percent and Millions US\$)

\begin{tabular}{|c|c|c|c|c|}
\hline Simulations & Base Value (Millions US\$) & Post Shock Effects & Change in GDP & Percentage Change \\
\hline GSP Plus status with Quota Restrictions & 143169.594 & 143191.188 & 21.594 & 0.015 \\
\hline EBA Status & 143169.594 & 144053.641 & 884.047 & 0.617 \\
\hline
\end{tabular}

Similarly, Table 3 presents the changes in real output of different sectors of Pakistan after both simulations. The results of both simulations reveal mixed effects on the real output of commodities. The results of the first simulation show that there are 13 sectors out of 38 where output level is increased with maximum increase in services sector (US\$ 0.383 million). The other major winning sectors are construction US $\$ 0.356$ million, sugar US\$ 0.199 million, vegetable, fruit and nuts US\$ 0.196 million, livestock and meat products US\$ 0.125 million. While there is decrease in real output in rest of the sectors. The prominent sectors with decrease in output include machinery and equipment US\$ -2.117 million, metals and products US\$ -1.875 million, leather products US\$ -1.777 million and oil seeds with US\$ -1.722 million.

The results of the second simulation show increase in real output in 25 sectors of Pakistan economy. The results reveal that paddy rice show maximum gain with US\$ 2.080 million followed by construction sector (US\$1.14 million), services sector (US\$1.26 million), mineral products nec (US\$ 0.96 million) and processed food (US\$ 0.93 million). While there is deterioration in the 11 sectors. The prominent sectors with decrease in output include leather products with US\$ -1.99 million, plant based fibers with US\$-1.60 million and textiles with US\$ -1.99 million.

The results of second simulation are more encouraging than Simulation 1 which means that if Pakistan is allowed to export in EU28 without any restriction, the real output level will increase in most of the sectors of the economy. 


\section{Exports and Imports}

The duty free and quota free entry of Pakistan into the EU28 is expected to bring positive effects on the exports of Pakistan. Similarly, the flow of imports will also increase due to increased demand of foreign inputs and resultant higher prices of many goods. Figure 2 explains the results of the simulations. The results of both simulations show an increase in imports and reduction in exports resulting disturbance in the trade balance. The exports of Pakistan to EU28 reduced by -1.79 percent in case of first simulation while in case of second simulation, the reduction is -1.282 percent. This reduction is export is due to

\begin{tabular}{|c|c|c|c|c|c|}
\hline \multirow[t]{3}{*}{ Commodity } & \multirow[t]{3}{*}{ Base Value (Millions US\$) } & \multicolumn{2}{|c|}{ GSP Plus with EU Capping (Quota) } & \multicolumn{2}{|c|}{ Potential EBA Status } \\
\hline & & Changes ir & Change in & Changes in & Change in \\
\hline & & Value & Percent & Value & Percent \\
\hline pdr & 1489.76 & -0.205 & -0.01 & 2.08 & 0.14 \\
\hline wht & 2616.37 & -0.102 & 0 & -0.12 & 0 \\
\hline gro & 181.39 & -0.02 & -0.01 & 0.46 & 0.26 \\
\hline v_f & 7201.54 & 0.196 & 0 & 0.17 & 0 \\
\hline osd & 365.22 & -1.722 & -0.47 & -0.76 & -0.21 \\
\hline Sugar & 5895.7 & 0.087 & 0 & -0.11 & 0 \\
\hline $\mathrm{pfb}$ & 2953.45 & -0.796 & -0.03 & -1.6 & -0.05 \\
\hline ctl & 4271.85 & 0.016 & 0 & 0.23 & 0.01 \\
\hline Animalprod & 20862.25 & 0.125 & 0 & 0.25 & 0 \\
\hline frs & 291.25 & 0.027 & 0.01 & -0.07 & -0.02 \\
\hline fsh & 879.47 & 0.076 & 0.01 & 0.27 & 0.03 \\
\hline minerals & 630.01 & -0.396 & -0.06 & 0.2 & 0.03 \\
\hline oil & 1468 & -0.318 & -0.02 & -0.23 & -0.02 \\
\hline Meatfood & 5029.13 & -0.357 & -0.01 & 0.93 & 0.02 \\
\hline vol & 3506.79 & -0.528 & -0.02 & -0.21 & -0.01 \\
\hline mil & 4373.73 & 0.073 & 0 & 0.62 & 0.01 \\
\hline $\operatorname{sgr}$ & 5333.85 & 0.199 & 0 & 0.65 & 0.01 \\
\hline b_t & 3618.37 & 0.117 & 0 & 0.67 & 0.02 \\
\hline tex & 23984.3 & -1.208 & -0.01 & -1.11 & 0 \\
\hline wap & 4404.37 & -1.296 & -0.03 & -0.91 & -0.02 \\
\hline lea & 1203 & -1.777 & -0.15 & -1.99 & -0.17 \\
\hline Wood & 2418.66 & -0.628 & -0.03 & 0.28 & 0.01 \\
\hline p_c & 8120.48 & -0.24 & 0 & 0.53 & 0.01 \\
\hline crp & 4289.23 & -1.07 & -0.02 & 0.22 & 0.01 \\
\hline $\mathrm{nmm}$ & 5498.41 & 0.119 & 0 & 0.96 & 0.02 \\
\hline Metals & 2107.05 & -1.875 & -0.09 & 0.19 & 0.01 \\
\hline Autoparts & 2733.24 & -0.569 & -0.02 & 0.55 & 0.02 \\
\hline ele & 2672.3 & -0.795 & -0.03 & 0.58 & 0.02 \\
\hline ome & 420.68 & -2.117 & -0.5 & -0.94 & -0.22 \\
\hline omf & 1111.31 & -1.151 & -0.1 & 0.28 & 0.03 \\
\hline utilities & 22303.91 & -0.216 & 0 & 0.66 & 0 \\
\hline cns & 16914.6 & 0.356 & 0 & 1.14 & 0.01 \\
\hline trd & 21665.48 & -0.133 & 0 & 0.39 & 0 \\
\hline Transport & 18768.37 & -0.036 & 0 & 0.64 & 0 \\
\hline $\mathrm{cmn}$ & 3009.44 & 0.058 & 0 & 0.76 & 0.03 \\
\hline All services & 55321.8 & 0.383 & 0 & 1.26 & 0 \\
\hline
\end{tabular}

production capacity of Pakistan in 2007 which was adversely affected by load shedding. The adverse effects of energy crises increased the production cost in Pakistan resulting into decline in exports. Due to this reason, the results of the simulations produced negative impacts.

The results of both simulations show a positive increase in the imports of Pakistan. The increase is 0.558 percent in case of first simulation, while in case of second simulation, the increase is 1.153 percent. This increase in imports is also a result of increased cost of production in Pakistan. Similarly, in order to increase the production, Pakistan would also 
require more inputs to import.

Figure 2 shows that the trade balance is highly deteriorated in case of first simulation while in case of second simulation, increase in imports is slightly less than the decrease in exports. This is because the quota restriction will restrict exports to EU28, leaving more products available for the domestic consumer to consume. Hence imports increased at lower rate. While in case of EBA status, there is no restriction to export resulting into reduced availability of domestic products. The reduction in availability and increased demand of imported inputs, increase the overall imports of the country.

Figure 2

Merchandise Exports and Imports of Pakistan (Percent)

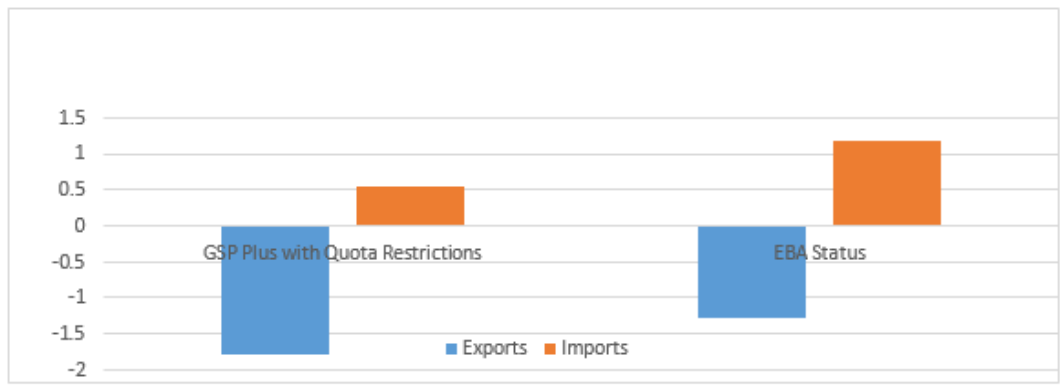

\section{Impact on Pakistan's Terms of Trade}

Terms of trade is define as the ratio of prices that a country receives and pays in exchange of its exports and imports. It is considered important to understand the impact of change in price on the welfare of public generally. Current study investigated the impact of two different simulations on the change in price of imports and exports. Pakistan has already achieved the status of GSP plus in EU28, the restriction free exports from Pakistan in case of GSP plus and EBA, may increase the export price of Pakistani products. Similarly, applying quota restriction may increase the price level at lower rate.

Figure 2 explains the effects of different simulations performed on the Pakistan's termsof-trade. The results of both simulations are positive but very different. In case of first simulation the export prices that Pakistan receives from EU28 are 0.019 percent higher than the import prices that Pakistan pays to the EU28.

Highest gain is seen in the results of simulation 2, assuming that if Pakistan gets the status of EBA in EU28 just like Bangladesh. Due to this status, the exports from Pakistan may increase rapidly resulting an increase in export prices. Hence, the results of this simulation show that Pakistan is receiving 1.834 percent higher export price than it is paying for its imports from EU28. 


\section{Changes in Household Income}

The study has discussed the impact of two simulations by using MyGTAP focusing on the issues of trade, GDP, output and prices. A unique feature of the MyGTAP model used in this study is the capability to disaggregate the regional household into both private and government entities (Minor \& Walmsley, 2013). The study disaggregated the regional household of standard GTAP model into 18 types to conduct a detailed analysis. The simulations used in the study will calculate the effects on household income distribution and expenditures. The data and weights required were obtained from the latest comprehensive Pakistani Social Accounting Matrix (SAM) 2007-08.

Figure 3

Changes in Term of Trade (TOT) of Pakistan, Constant 2007 Prices, (Percent)

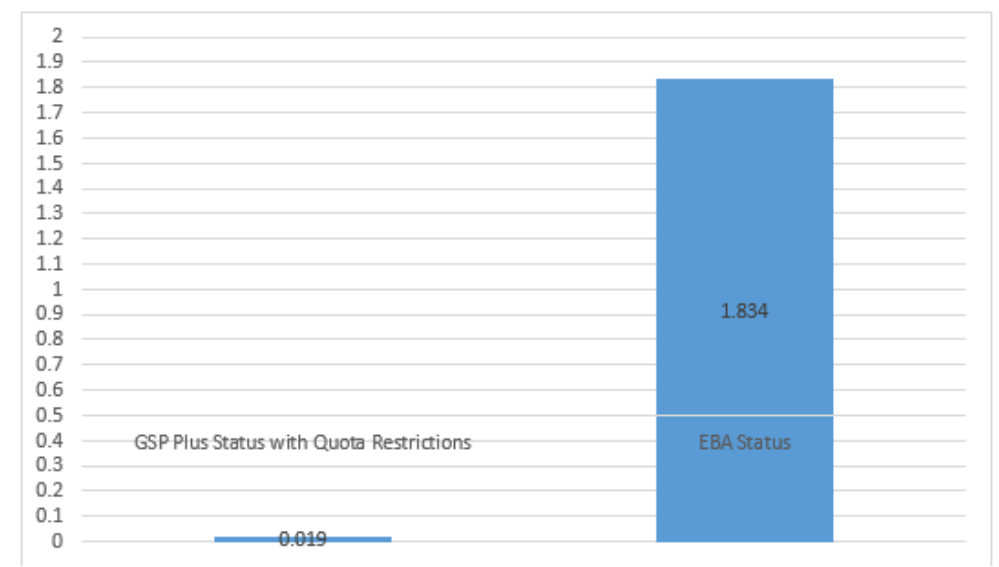

\section{Changes in Household Income}

The study has discussed the impact of two simulations by using MyGTAP focusing on the issues of trade, GDP, output and prices. A unique feature of the MyGTAP model used in this study is the capability to disaggregate the regional household into both private and government entities (Minor \& Walmsley, 2013). The study disaggregated the regional household of standard GTAP model into 18 types to conduct a detailed analysis. The simulations used in the study will calculate the effects on household income distribution and expenditures. The data and weights required were obtained from the latest comprehensive Pakistani Social Accounting Matrix (SAM) 2007-08.

While conducting the welfare analysis, the studies that employ CGE models, normally show all household are equally affected due to any change in the trade policy. In case of MyGTAP, the households are distributed into categories aiming to calculate the impact on the marginalized population before designing a trade policy. Any change in wage rate 
is considered a change in the household income. The household income consist of income coming from different factors, so any change in income of factors means a change in income of household.

The results of both simulations are summarized in Figure 4 which show a positive change in overall household income. There is a change of 0.74 percent in case of first simulation but in case of second the change is 2.17 percent which means that if Pakistan is allowed to export duty free and quota free into the EU28, the household income in Pakistan will rise.

Figure 4

Changes in Households Income in Pakistan, Constant 2007 Prices (Percent)

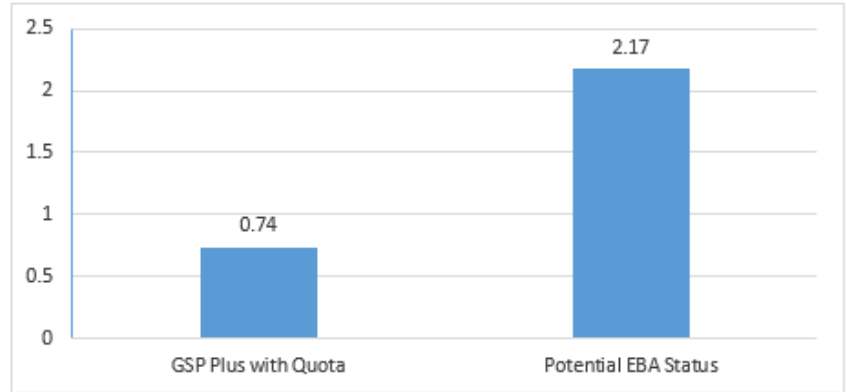

The results of both simulations are summarized in Figure 4 which show a positive change in overall household income. There is a change of 0.74 percent in case of first simulation but in case of second the change is 2.17 percent which means that if Pakistan is allowed to export duty free and quota free into the EU28, the household income in Pakistan will rise.

The results below show change in all 18 categories of households. The regional household is divided into three categories, household in Punjab, household in Sindh and household in rest of the Pakistan. The results further reveals that that every household is not equally affected. There are some household better off and vice versa.

\section{Household Income of Large and Medium Farm}

Table 4 represents the results of both simulations in order to check their impact on the income of large and medium household of Pakistan. The results reveal that in case of first simulation, the household other than Sindh and Punjab have positive change of 0.029 percent in its income while the income of household in Sindh is reduced by -0.478 percent and in Punjab by -0.239 percent. On the other hand, the income of all household increases with maximum 2.347 percent increase in household of rest of the Pakistan (excluding Sindh and Punjab provinces). 
Table 4

Changes in Household Income of Large and Medium Farm, Constant 2007 Prices (Percent)

\begin{tabular}{|c|c|c|c|c|c|}
\hline Household Types & HH Code & Population (millions) & Income shares (percent) & GSP Plus with Quota & Potential EBA Status \\
\hline Large and medium farm Sindh & H-MF1 & 0.8 & 1.5 & -0.478 & 1.831 \\
\hline Large and medium farm Punjab & $\mathrm{H}-\mathrm{MF} 2$ & 2.4 & 6.1 & -0.239 & 1.613 \\
\hline Large and medium farm other & H-MF3 & 0.6 & 0.8 & 0.029 & 2.347 \\
\hline
\end{tabular}

\section{Income of Small Farm Household}

The results of the both simulations are presented in Table 5 which show the impact on the small household living in Pakistan. The results reveal that small farmer living anywhere in Pakistan is befitted in both cases. The results further reveal that the farmer living in parts other than Sindh and Punjab is benefitting maximum in case of both simulations while the small farm household in Sindh is getting minimum benefits in both cases. The maximum benefit that small farm household of other Pakistan is getting is 2.253 percent which is in case of Simulation 2 (if Pakistan gets the EBA status in EU28) and small farm household of Sindh is getting minimum benefit of 0.331 percent in case of first simulation (applying quota restrictions to justify the capping mechanism of EU28 after GSP plus status of Pakistan).

Table 5

Changes in Household Income of Small Farmers, Constant 2007 Prices (Percent)

\begin{tabular}{lccccc}
\hline Household Types & HH Code & Population (millions) & Income shares (percent) & GSP Plus with Quota & Potential EBA Status \\
\hline Small farm Sindh & H-SF1 & 3.1 & 1.8 & 0.331 & 2.146 \\
Small farm Punjab & H-SF2 & 16 & 11.5 & 0.487 & 2.179 \\
Small farm other Pakistan & H-SF3 & 5.6 & 3.3 & 0.885 & 2.253 \\
\hline
\end{tabular}

\section{Income of Landless Farmer Household}

In this section, we will discuss the rural household that is farmer but do not own a piece of agriculture land in any area of Pakistan. The results of both simulations are presented in Table 6 that show a positive change in income of all rural households that are landless but are farmers. In case of first simulation landless farmer of Sindh is gaining minimum (0.405 percent) while the landless farmer of rest of the Pakistan is gaining maximum (0.954 percent). The results of second simulation show that landless farmer of Punjab is gaining maximum (2.452 percent) while the landless farmer of Sindh is gaining minimum (2.08 percent).

Table 6

Changes in Household Income of Landless Farmers, Constant 2007 Prices (Percent)

\begin{tabular}{lccccc} 
Household Types & HH Code & Population (millions) & Income shares (percent) & GSP Plus with Quota & Potential EBA Status \\
\hline Landless farmers Sindh & H-OF1 & 2.5 & 1.4 & 0.405 & 2.08 \\
Landless farmers Punjab & H-OF2 & 3.6 & 1.8 & 0.68 & 0.954 \\
Landless farmers other Pakistan & H-OF3 & 1.7 & 0.7 & 2.452 \\
\hline
\end{tabular}




\section{Income of Landless Labor}

The household living in rural areas of Pakistan working in agriculture farms as a laborer and having no land is included in landless labor. The results showing the impact of both simulations on the household income of landless agriculture labor of Pakistan are presented in Table 7. The results show maximum gain for the landless labor of whole Pakistan in both simulations as compared to any other household. In case of first simulation maximum gain is shown in for the landless agriculture labor of Sindh (1.563 percent) while the landless agriculture labor of Punjab is getting minimum gain (1.432 percent). In case of second simulation, the results are quite similar with maximum gain again in case of landless agriculture labor of Sindh (4.136 percent) while the landless agriculture labor of Punjab is getting minimum gain (3.512 percent).

Table 7

Changes in Household Income of Rural Agricultural Labor, Constant 2007 Prices (Percent)

\begin{tabular}{lccccc}
\hline Household Types & HH Code & Population (millions) & Income shares (percent) & GSP Plus with Quota & Potential EBA Status \\
\hline Landless agri. Lab Sindh & H-AGW1 & 3 & 1.5 & 1.563 & 4.136 \\
Landless agri. Lab Punjab & H-AGW2 & 3.3 & 1.4 & 1.432 & 3.512 \\
Landless agri. Lab other Pakistan & H-AGW3 & 0.4 & 0.2 & 1.498 & 3.944 \\
\hline
\end{tabular}

\section{Income of Rural Non-farm Household}

In rural areas of Pakistan, there are households that have no direct connection with agriculture farming. The results shown in Table 8 reveal the impact of both simulations on the income of non-farm rural households. The rural non-farm household of Sindh gets minimum gain (0.994 percent) in case of first simulation while rest of the rural non-farm households in Pakistan gain (0.997 percent). Similarly, in case of second simulation, rural non-farm households of Sindh get maximum gain (1.569 percent) and minimum gain (1.356 percent) in case of rural non-farm households of rest of the Pakistan.

Table 8

Changes in Household Income of Rural Non-farm Household, Constant 2007 Prices (Percent)

\begin{tabular}{lccccc}
\hline Household Types & HH Code & Population (millions) & Income shares (percent) & GSP Plus with Quota & Potential EBA Status \\
\hline Rural non-farm quintile 1 & H-NFQ1 & 8.2 & 2.8 & 0.994 & 1.569 \\
Rural non-form quintile 2 & H-NFQ2 & 8.9 & 3.3 & 0.997 & 1.539 \\
Rural non-farm quintile other & H-NFOTH & 27.7 & 17.3 & 0.997 & 1.356 \\
\hline
\end{tabular}

\section{Income of Urban Household}

Table 9 show the impact of both simulations on the urban household of Pakistan. The urban household of Sindh is showing maximum gain in both simulations (0.935 percent and 1.342 percent respectively) while minimum gain is seen in the income of urban household of rest of the Pakistan in case of both simulations (0.86 percent and 1.162 percent respectively). 
Changes in Household income of Urban Household, Constant 2007 Prices (Percent)

\begin{tabular}{lccccc}
\hline Household Types & HH Code & Population (millions) & Income shares (percent) & GSP Plus with Quota & Potential EBA Status \\
\hline Urban quintile 1 & H-UQ1 & 8.6 & 2.6 & 0.935 \\
Urban quintile 2 & H-UQ2 & 8.6 & 3.4 & 0.927 \\
Urban other & H-UOTH & 25.7 & 38.7 & 0.86 & 1.342 \\
\hline
\end{tabular}

Overall, factor income remains positive for almost all households. If there is no tariff and quota restriction from EU28, the income of every household type will increase but that increase. Primarily, it is because, the increased exports of Pakistan will definitely increase the economic activities in the economy and the backward and forward linkages of the industry will bring positive change in the income of every household.

\section{Effects on Real Returns to Factors}

Increased trade and especially exports increase the rate of return to factors. The HeckscherOhlin model is although workable only in the economies where amount of goods and the number of production factors is equal. The products are assumed homogenous in the model, despite many markets in the world are represented in a better way with differentiated products (Suranovic, 2010). In case of Pakistan, the model suggests that there will be decreases in the return to capital as country is already capital deficient as compare to its competitors (Khan et al., 2015).

Labor force of Pakistan is more than 65 million. Unemployment rate in Pakistan is about 6 percent (Government of Pakistan, 2015). Despite tremendous Government efforts for ensuring minimum wages in Pakistan like "Minimum Wages Ordinance 1961, the Punjab Minimum wages for unskilled Workers Ordinance 1969, Minimum Wages Board," etc ensure that Government is dedicated to support low income groups.

The model used for the calculation of effects on real returns to factors is the extension of standard GTAP model and uses the Armington assumption that categories the products on the basis of country of origin. Furthermore, assimilation could disturb the rate of return on capital by virtue of the prices of transitional and capital goods.

The results of both simulations show the change in factor prices with respect to the price index for private consumption expenditure. However, it fails to consider the impact of changes in government's revenue, and government's capacity to redistribute tax income to individuals, whether it is through transfer payments or provision of public goods (Khan et al., 2015).

\section{Wages of Large Agriculture Land Owned Labor}

The results of both simulations are presented in the Table 10 showing changes in the wages of household that owns large agricultural land. The results reveal that in case of first simulation, the wage of labor decrease by -1.45 percent while in case of second simulation, it increased by 0.283 percent. 
Table 10

Changes in Household income of Urban Household, Constant 2007 Prices (Percent)

\begin{tabular}{lllcc}
\hline Factor & RF Code & Description & GSP Plus with Quota & Potential EBA Status \\
\hline Labor & LA-AGL & Labor - agric (own)-large & -1.45 & 0.283 \\
\hline
\end{tabular}

\section{Wages of Medium Agriculture Land Owned Labor}

The results in Table 11 show the changes in the wages of labor that own medium size piece of agriculture land, after performing both simulations. The results show that in case of first simulation, the wage of labor with medium sized agriculture land decreased by -1.335 percent in the region of Punjab. The results of second simulation show that wage of all households with medium sized agriculture land increased with maximum increase in the case of labor living in parts of Pakistan other than Punjab and Sindh and that is 1.487 percent.

\section{Table 11}

Change in Real Wages of Medium Agriculture Land Owned Labor (Percent)

\begin{tabular}{lllcc}
\hline Factor & RF Code & Description & GSP Plus with Quota & Potential EBA Status \\
\hline \multirow{4}{*}{ Labor } & LA-MF1 & Labor - agric (own)-med Sindh & -1.244 & 1.184 \\
& LA-MF2 & Labor - agric (own)-med Punjab & -1.335 & 0.285 \\
& LA-MF3 & Labor - agric (own)-med OPak & -0.956 & 1.487 \\
\hline
\end{tabular}

\section{Wages of Small Agriculture Land Owned Labor}

In case of farmers having small area of agriculture land in all areas of Pakistan, the results seem quite similar to the case of farmers having medium sized agriculture land. The results of both simulations are shown in Table 12. According to the results, the wages of the labor with small size agriculture farm decreased everywhere in Pakistan when country faces quota restrictions in the EU while a positive change can be seen in case of Simulation 2 i.e. if Pakistan gets the status of EBA in the EU28.

Table 12

Change in Real Wages of Small Agriculture Land Owned Labor (Percent)

\begin{tabular}{lclcc}
\hline Factor & RF Code & Description & GSP Plus with Quota & Potential EBA Status \\
\hline \multirow{3}{*}{ Labor } & LA-SF1 & Labor - agric (own)-sm Sindh & -1.227 & 1.136 \\
& LA-SF2 & Labor - agric (own)-sm Punjab & -1.017 & 0.851 \\
& LA-SF3 & Labor - agric (own)-sm OPak & -0.454 & 1.577 \\
\hline
\end{tabular}

\section{Wages of Skilled and Unskilled Labor}

One additional simulation is added in the study by assuming unskilled labor is unemployed in the model and then performing both simulations to check what would be the impact on real wages of other types of labors. The impact of both simulations on the wage of skilled and unskilled labor is shown in the Table 13. The results show that in case of first simulation, the wage of agriculture labor in general is increased by 1.355 percent, in case of 
unskilled non-agriculture labor, the wage increased by 0.286 percent and in case of skilled non-agriculture labor, it is increased by 0.304 percent.

The results of the second simulation are quite different where the wage of non-agriculture unskilled labor is decreased by -1.851 percent while a maximum increase is seen in the agriculture labor (5.366 percent)

Table 13

Change in Real Wages of Skilled and Unskilled Labor (Percent)

\begin{tabular}{lllcc}
\hline Factor & RF Code & Description & GSP Plus with Quota & Potential EBA Status \\
\hline \multirow{4}{*}{ Labor } & LA-AGW & Labor - agric (wage) & 1.355 & 5.366 \\
& LA-SKU & Labor - non-ag (unsk) & 0.286 & -1.851 \\
& LA-SK & Labor - non-ag (skilled) & 0.304 & 0.075 \\
\hline
\end{tabular}

It is worthy to note that the supply of labor is fixed in the agriculture sector, so any decrease in demand may decrease the wage of the agriculture labor. The results of the simulations show that the increase in wage of skilled labor is greater than the increase in wage of unskilled labor. Similarly, the supply of production labor is also fixed which results into increase in wage rate as the production demand increases. The results of the simulations show that increased exports will increase the wage rate which opposes the theory that liberalized trade may reduce the wage rate. For further information, please see (Stiglitz, 1970; Davis, 1996; Feenstra \& Hanson, 1997; Topalova, 2005; Harrison, 2006).

Majority of the exports from Pakistan are textile and agricultural products so increased volume of exports due to GSP plus and EBA status in the EU28, might shift labor from the agriculture to industry. This is primarily due to the fact that land is sector specific but labor is inter-sectorally mobile. So this offset effect might lead industrialization in Pakistan.

\section{Real Return to Land of Large Agriculture Farms}

After labor, land is another factor of production, the rent paid to land is also affected by certain changes in the trade. The source land is fixed, so any change in demand for the production of goods requiring more land, may result into change in return to land. The results shown is Table 14 reveal the effects of both simulations on the large land farms. The results of first simulation show a negative change in the real return to land in case of large farms everywhere in Pakistan but in case of Simulation 2, the large land farm of Punjab is losing in return while a positive change is seen in the farms of Sindh $(0.464$ percent) and rest of the Pakistan (2.053 percent) which is maximum gain.

Table 14

Change in Real Return to Land of Large Farms (Percent)

\begin{tabular}{lllcc}
\hline Factor & RF Code & Description & GSP Plus with Quota & Potential EBA Status \\
\hline \multirow{4}{*}{ Land } & LN-LG1 & Land - large- Sindh & -1.252 & 0.464 \\
& LN-LG2 & Land - large- Punjab & -1.639 & -0.175 \\
& LN-LG3 & Land - large - OthPak & -1.085 & 2.053 \\
\hline
\end{tabular}




\section{Real Return to Land of Medium Agriculture Farms}

The case of change in real return to the land of medium farms is a little bit different than the previous case. The results of both simulations are presented in Table 15 that show a reduction in return to the land of medium farms in case of first simulation. The maximum reduction in return is seen in the province of Punjab (-1.338 percent). While in case of second simulation, the results are quite encouraging. There is gain in return to the land of medium farms in all areas of Pakistan with maximum gain in return of 1.467 percent in the region other than Punjab and Sindh.

Table 15

Change in Real Return to Land of Medium Farms (Percent)

\begin{tabular}{lllcc}
\hline Factor & RF Code & Description & GSP Plus with Quota & Potential EBA Status \\
\hline \multirow{4}{*}{ Land } & LN-MD1 & Land - irrigated - med Sindh & -1.228 & 1 \\
& LN-MD2 & Land - irrigated - med Punjab & -1.338 & 0.359 \\
& LN-MD3 & Land - irrigated - med OthPak & -0.951 & 1.467 \\
\hline
\end{tabular}

\section{Real Return to the Land of Small Agriculture Farms}

The results of both simulations relating to change in return to the land of small farms are presented in Table 16 which are quite similar to the results of medium size farms. The gain is negative in case of first simulation for all regions of Pakistan with maximum loss in return in the province of Sindh (-1.215 percent). The results of the second simulation are opposite to the first simulation that show a gain in return to the land of small farms in all areas of Pakistan. The maximum gain is seen in the areas other than provinces of Punjab and Sindh that is 1.613 percent.

Table 16

Change in Real Return to Land of Small Farms (Percent)

\begin{tabular}{lllcc}
\hline Factor & RF Code & Description & GSP Plus with Quota & Potential EBA Status \\
\hline \multirow{4}{*}{ Land } & LN-SM1 & Land - irrigated - sm Sindh & -1.215 & 0.977 \\
& LN-SM2 & Land - irrigated - sm Punjab & -1.022 & 0.942 \\
& LN-SM3 & Land - irrigated - sm OthPak & -0.399 & 1.613 \\
\hline
\end{tabular}

\section{Real Return to the Land of Non-Irrigated Agriculture Farms}

There are certain areas in Pakistan where traditional canal system is not activated to irrigate the agriculture land. Those farms are called non-irrigated farms. The results of both simulations are presented in Table 17 to show the return to the land of non-irrigated farms. Interestingly the results are very similar to the results of previous two cases (land of medium and small farms). In case of first simulation, there is negative gain in all areas of Pakistan where non-irrigated farms exist with loss of -1.12 percent in the province of Sindh while in rest of the Pakistan the non-irrigated land suffered from loss of -1.337 percent in return. The case of second simulation shows gain in return of the non-irrigated land with maximum gain in the Sindh province (0.821 percent) whereas in rest of the Pakistan, the non-irrigated land gain 0.708 percent in return. 
Table 17

Change in Real Return to Land of Non-Irrigated Farms (Percent)

\begin{tabular}{lllcc}
\hline Factor & RF Code & Description & GSP Plus with Quota & Potential EBA Status \\
\hline \multirow{4}{*}{ Land } & LN-DR1 & Land non-irrig - sm/m Sindh & -1.12 & 0.821 \\
& LN-DR2 & Land non-irrig - sm/m Punjab & -1.337 & 0.708 \\
& LN-DR3 & Land non-irrig - sm/m OthPak & -1.337 & 0.708 \\
\hline
\end{tabular}

It is interesting to note that the results of first simulation suggest a negative gain in return to land which also support the results of (Bradley \& Norman, 1977) while working on US economy. While these are contradictory with the findings of Hong (1990) which suggested that protection increases the return as resources shift towards agricultural productivity. The gain is not possible without technonolgy whether economy is facing restrictions or not (Ghosh, 2004). The Stolper Samuelson Theorem that is based on the famous Heckscher-Ohlin model also supports the results that liberalized trade lead to increase in return to land (Leamer et al., 1995). Similarly, a large majority of researchers support the results that return on land increases if there is no restrictions on the exports of an economy, for example see (Runge \& Halbach, 1990; Chang, 1979).

\section{Real Return to the Capital}

We have already discussed the impact of both simulations on the return to labor and land. In this section, we will focus on the factor of capital. The study has divided the capital into four categories and results along with categories are presented in Table 18. The results of both simulations show gain in return to capital in most of the types except capital other than agriculture (-1.106 percent in case of quota restriction on Pakistan) and capital formation (-0.054 percent in case if Pakistan gets EBA status in EU28). In case of both simulation, the maximum gain is seen in capital livestock, 1.818 percent when quota is applied on exports from Pakistan to justify the capping mechanism of EU28 and 6.24 percent gain in return if Pakistan gets the status of EBA in EU28.

Table 17

Change in Real Return to Land of Non-Irrigated Farms (Percent)

\begin{tabular}{lllcc}
\hline Factor & RF Code & Description & GSP Plus with Quota & Potential EBA Status \\
\hline \multirow{4}{*}{ Capital } & K-LVST & Capital livestock & 1.818 & 6.24 \\
& K-AGR & Capital other agriculture & -1.106 & 0.798 \\
& KFORM & Capital formal & 0.105 & 0.105 \\
& KINF & Capital informal & 0.28 & -0.054 \\
\hline
\end{tabular}

The results of both simulation suggest that there is gain in return to capital in most of the cases which support the work of researchers like (Chang, 1979; Hong, 1990; Thompson, 2016). Walmsley et al. (2013); Khan et al. (2015) also produced the same results while studying the Mozambique and Pakistan economy respectively. Although Ghosh (2004) also support this but adds that gain in return to the capital can be maximized with continuous improvement in the technology. 


\section{Limitations of the Study}

Parallel to many empirical studies, this study was constrained by a variety of factors which could be considered as limitations. The first and the most important limitation is the database, similar to most other studies which adopt CGE models. Current study used GTAP v 9.0 and Social Accounting Matrix with base year 2007-08. This extension of standard GTAP model is known as MyGTAP which provided the parameters related to trade elasticity but these parameters are not estimated econometrically. It is noted that household welfare results are sensitive to parameter values assumed in the model. Likewise, a superior understanding of implications at household level could have been achieved if we had been able to use more disaggregated data at household level.

Despite the above mentioned limitations, the global CGE model (standard GTAP) generated reasonable good results at macro level for the country and the MyGTAP model with the most latest constructed SAM (2007-08) for Pakistan. The results could be more practical with current data.

\section{Conclusion and Policy Recommendations}

The study has attempted to calculate whether the GSP plus status of Pakistan in the EU28 produce positive change not only at aggregate level but also at household income and real wages. The study attempted to calculate the effects of different potential and current opportunities for Pakistan by using standard MyGTAP. The MyGTAP employed the latest available Social Accounting Matrix (SAM) with base year 2007-08.

The descriptive analysis of the results of different simulations MyGTAP reveal that there is overall increase in the GDP of Pakistan. The incentive to export in the EU28 will increase the production level in the Pakistan. Similarly, the improvement in production also increase the real wages and household income. Similarly, EBA status of Pakistan in the EU28 show an increase in the household income with maximum gain by the household of rural Sindh with no agriculture land and a positive change in real wages of most of the factors. Comparatively low improvement over urban and non-farm household of rural areas. Therefore, empirical evidence in terms of the household welfare from this study supports the overall view that Pakistan can gradually gain from GSP plus status.

The policy implications for the study are straightforward and related to trade policy which is also the main concern of the research. The competition after the GSP plus implementations have been improved, so the country needs to improve the competitiveness. For this purpose, it should be acknowledged that it is firm that can bring success for the country only if it works under right strategies and clear vision about how and why to produce and for which target market it is producing. Therefore, the firms wishing to enter into tough competition require very supportive role from the public authorities in the Pakistan. The public authorities should ensure the provision of safe and healthy working environment that may enable firms to compete at domestic and finally in the world market. The production activities of the country are concentrated towards the sectors of textiles, wearing apparel, beverages and tobacco and leather products that need to be diversified with cost effective methods. Moreover, Pakistan can focus on those markets where its 
competitors have a small share. 


\section{References}

Ahmed, V., \& O'Donoghue, C. (2008). Welfare impact of external balance in Pakistan: CGE-micro simulation analysis (Tech. Rep.). Marina Congress Centre in Helsinki, Finland.

Bradley, I. G., \& Norman, G. (1977). Welfare effects of trade restrictions. Elsevier, Netherlands.

Burfisher, M. E. (2011). Introduction to computable general equilibrium models. Cambridge University Press, England.

Butt, M. S. (2006). Impact of tariff cuts on Pakistan: a computable general equilibrium analysis with particular focus on main exports and regional disparities (Unpublished doctoral dissertation). Griffith University, Australia.

Carbone, M., \& Orbie, J. (2016). The trade-development nexus in the European Union: differentiation, coherence and norms. Routledge, United Kingdom.

Chang, W. W. (1979). Some theorems of trade and general equilibrium with many goods and factors. Econometrica, $47(3), 709$. doi: 10.2307/1910416

Davis, D. (1996). Trade liberalization and income distribution (Tech. Rep.). Retrieved from http://dx.doi.org/10.3386/w5693

Debowicz, D., Dorosh, P., Haider, H. S., \& Robinson, S. (2007). A 2007-08 social accounting matrix for Pakistan. SSRN Electronic Journal. Retrieved from http://dx.doi.org/ 10.2139/ssrn. 2161402

Dorosh, Niazi, M., \& Nazli, H. (2004). A social accounting matrix for Pakistan, 2001-02: Methodology and results. a background research paper for the Pakistan rural factor markets study, World Bank (Tech. Rep.).

Dorosh, \& Rashid, S. (2013). Domestic Terms of Trade for Agriculture in Pakistan and Agricultural Income Tax. IFPRI. (Tech. Rep.). Retrieved from http://pssp.ifpri.info/files/2013/05/Domestic-tems-of-trade -for-agriculture-in-Pakistan-and-agriculture-income-tax.pdf

European, C. (2013). The EU's new Generalised Scheme of Preferences (GSP) (Tech. Rep.). Retrieved from http://trade.ec.europa.eu/doclib/docs/2013/ february/tradoc_150582.pdf

Feenstra, R. C., \& Hanson, G. H. (1997). Foreign direct investment and relative wages: Evidence from Mexico's maquiladoras. Journal of International Economics, 42(3), 371-393.

Ghosh, N. (2004). Impact of trade liberalization on returns from land: A regional study of Indian agriculture. In The WTO, developing countries and the Doha development agenda (pp. 92-129). Springer Nature. Retrieved from http://dx.doi.org/ 10.1057/9780230523265_5 doi: 10.1057/9780230523265_5

Harrison, A. (2006). Globalization and poverty (Tech. Rep.). National Bureau of Economic Research, University of Chicago.

Hertel, T. W., \& Hertel, T. W. (1997). Global trade analysis: modeling and applications. Cambridge University Press, England.

Hong, W. (1990). Export-oriented growth of Korea: a possible path to advanced economy. International Economic Journal, 4(2), 97-118. 
Hussain, N. (2010). The potential impact of trade liberalization and fiscal strictness on households' welfare and inequality in Pakistan (Unpublished doctoral dissertation). University of Dundee, Scotland.

Khan, M. A., Saboor, A., Mohsin, A. Q., et al. (2015). Impact of agricultural trade liberalization on income inequality in Pakistan. Pakistan Journal of Agricultural Research, 28(1), 28-37.

Kuiper, M., \& Shutes, L. (2014). Expanding the household coverage of global simulation models: an application to Ghana. (Tech. Rep.). Retrieved from http://www3.lei .wur.nl/FoodSecurePublications/TP3_kuiper.pdf

Leamer, E. E., et al. (1995). The heckscher-ohlin model in theory and practice. Princeton University, New Jersey.

Lofgren, H., Chulu, O., Sichinga, O., Simtowe, F., Tchale, H., Teska, R., \& Wobst, P. (2001). External shocks and domestic poverty alleviation: Simulations with a CGE model of Malawi (Tech. Rep.). International Food Policy Research Institute (IFPRI).

Minor, P., \& Walmsley, T. (2013). MyGTAP Data Program: A program for customizing and extending the GTAP Database (Tech. Rep.). GTAP Working Paper 79, Center for Global Trade Analysis, Purdue University, IN.

Naqvi, F. (1998). A computable general equilibrium model of energy, economy and equity interactions in Pakistan. Energy Economics, 20(4), 347-373.

Persson, M., \& Wilhelmsson, F. (2016). EU trade preferences and export diversification. The World Economy, 39(1), 16-53.

Rashid, N. (2006). Trade implications for Pakistan in the European Union Market in the Milieu of EU Enlargement from EU15 to EU25 (Unpublished doctoral dissertation). University of Glasgow, U.K.

Runge, C. F., \& Halbach, D. (1990). Export demand, U.S. farm income, and land prices. Land Economics, 66(2), 150-162.

Shaikh, F., \& Rahpoto, M. (2009). Impact of trade liberalization and SAFTA on Pakistan's Economy by Using CGE Model. International Journal of Business and Management, $4(4), 192-209$.

Siddig, K., Aguiar, A., Grethe, H., Minor, P., \& Walmsley, T. (2014). Impacts of removing fuel import subsidies in Nigeria on poverty. Energy Policy, 69, 165178. Retrieved from http://dx.doi.org/10.1016/j.enpol.2014.02.006 doi: 10.1016/j.enpol.2014.02.006

Siddiqui, R., \& Iqbal, Z. (1999). Tariff Reduction and Functional Income Distribution in Pakistan: A CGE Model. Islamabad (Tech. Rep.). Retrieved from http://pide.org .pk/Mimap/Report09.pdf

Stiglitz, J. E. (1970). Factor price equalization in a dynamic economy. Journal of Political Economy, 78(3), 456-488.

Suranovic, S. (2010). A moderate compromise: Economic policy choice in an era of globalization. Springer, Germany.

Thompson, H. (2016). Tariffs and wages in trade theory. Review of Development Economics, 20(2), 399-405.

Topalova, P. (2005). Trade liberalization, poverty, and inequality: Evidence from Indian districts (Tech. Rep.). Retrieved from http://dx.doi.org/10.3386/w11614 doi: 
$10.3386 / \mathrm{w} 11614$

Vanzetti, D., Huong, P. L., et al. (2006). Vietnam's trade policy dilemmas, The Ninth Annual Conference on Global Economic Analysis (Tech. Rep.). Retrieved from https://jgea.org/resources/download/2646.pdf

Walmsley, T., Minor, P., et al. (2013). MyGTAP model: A model for employing data from the MyGTAP data application-multiple households, split factors, remittances, foreign aid and transfers (Tech. Rep.). Purdue University, Indiana.

Winters, L. A., McCulloch, N., \& McKay, A. (2004). Trade liberalization and poverty: The evidence so far. Journal of Economic Literature, 42(1), 72-115. 